\title{
Torta de girassol na alimentação de matrizes \\ suínas em gestação e lactação
}

\section{Sunflower cake to sows feeding on gestation and lactation phases}

\author{
Guilherme Eduardo Gomes Pedreiro'; Caio Abércio da Silva ${ }^{2 *}$; \\ Ana Maria Bridi; Nilva Aparecida Nicolao Fonseca²; \\ João Waine Pinheiro²; José Maurício Gonçalves dos Santos ${ }^{4}$
}

\begin{abstract}
Resumo
Foram realizados dois experimentos visando avaliar a utilização da torta de girassol nas rações de matrizes suínas em final de gestação ( 80 a 110 dias de prenhez) e em matrizes em lactação (a partir do parto até o desmame aos 21 dias). Foram utilizadas 48 matrizes, 24 gestantes e 24 lactantes de mesma genética comercial. Os tratamentos consistiram na inclusão de 4 níveis de torta de girassol nas rações de gestação e lactação, sendo: 0,0; 5,0;10,0 e 15,0\% . O delineamento nos experimentos foi em blocos inteiramente casualizados, com quatro tratamentos e seis repetições, sendo o bloco representado pela ordem do parto. Cada matriz representou uma repetição. Foram avaliados a espessura de toucinho, o consumo diário de ração, o peso das placentas, o intervalo desmame-cio e parâmetros reprodutivos. Não foram observadas diferenças $(\mathrm{P}>0,05)$ sobre nenhum dos parâmetros estudados, exceto para o consumo de ração na fase de lactação que apresentou um efeito linear negativo. Conclui-se que a torta de girassol pode ser incluída em programas de alimentação de matrizes após os 80 dias de gestação e na lactação em níveis de até $20 \%$.
\end{abstract}

Palavras-chave: Alimento alternativo, desempenho produtivo, programa alimentar

\begin{abstract}
Two experiments were carried out to evaluate the use of sunflower cake in the rations to gestating and lactating sows. Forty eight sows, 24 gestating and 24 lactating, with the same genetic background were used. The treatments were represented by the levels of sunflower cake included in the rations of gestating and lactating sows, been: $0.0 ; 5.0 ; 10.0 ; 15.0 \%$. The experimental design for both experiments was a randomized block, with four treatments and six repetitions, been the block represented by the reproductive order. Each sow represented one repetition. The characteristics evaluated were back fat thickness, feed consumption, interval weaning to estrus, placenta's weight and reproductive parameters. No significant effects were observed on reproductive performance, except the feed consumption during the lactation that was observed a negative linear effect. The sunflower cake can be included until the level of $20 \%$ in feeding programs to sows after 80 -days of gestation and to the lactation phase.
\end{abstract}

Key words: Alternative feed, reproductive performance, feeding program

1 Mestrando do Programa de Pós-Graduação em Ciência Animal - Universidade Estadual de Londrina (UEL).

2 Professores Associados - Universidade Estadual de Londrina - Depto. de Zootecnia - CEP 86051-970 Londrina, PR, E-mail: casilva@uel.br.

3 Professora Adjunto - Universidade Estadual de Londrina - Depto. de Zootecnia - Londrina, PR.

4 Professor do CESUMAR, Maringá - PR

* Autor para correspondência 


\section{Introdução}

A suinocultura é uma atividade altamente dependente das commodities milho e farelo de soja, principais ingredientes utilizados nas rações e responsáveis por importante parcela dos custos de produção. Neste cenário, a busca por alimentos alternativos que possam substituir em equivalência qualitativa e econômica estes produtos é constante.

Dentre vários alimentos avaliados, recentemente, os co-produtos das indústrias do biocombustível têm despertado muita atenção. Neste particular, a cultura do girassol ganha evidência por representar uma das mais importantes bases agrícolas do programa nacional de combustíveis de fonte renovável.

Os principais sub-produtos resultantes da extração do óleo do grão de girassol são o farelo e a torta, sendo este último obtido pelo esmagamento do grão, isento do uso do hexano.

Tem-se constatado que a torta de girassol pode ser incluída na dieta de suínos na fase de crescimento e terminação em até 15\% (COSTA et al., 2005), todavia, há pouca informação sobre o seu uso para a alimentação de matrizes em fase de gestação e de lactação.

Um plano nutricional adequado para a matriz suína é responsável pelo seu equilíbrio endócrino e fisiológico, refletindo em maior sobrevivência embrionária, satisfatório desenvolvimento das glândulas mamárias e dos fetos, adequada recomposição das reservas corporais das multíparas, correto crescimento corporal das marrãs e nascimento de maior número de leitões (ZANGERONIMO; ALMEIDA; FIALHO, 2006).

Portanto, a avaliação da torta de girassol em programas alimentares para a matriz suína em fase de gestação e em lactação deve ser rigorosa. Neste sentido, o objetivo do presente trabalho foi avaliar os efeitos de diferentes níveis de inclusão de torta de girassol em dietas de matrizes suínas gestantes e lactantes sobre sua condição corporal e sobre seu desempenho reprodutivo.

\section{Material e Métodos}

Foram conduzidos dois experimentos em uma granja comercial localizada na cidade de Arapongas - PR. Foram utilizadas 48 matrizes suínas híbridas Naïma, da genética Pen Ar Lan, sendo 24 gestantes e 24 lactantes. No primeiro experimento foram avaliados os níveis de inclusão de torta de girassol nas dietas de matrizes gestantes e os reflexos produtivos na fase e na lactação subseqüente. $O$ período de fornecimento das rações experimentais foi de 30 dias, iniciando-se aos 80 dias e terminando aos 110 dias de gestação. As matrizes foram divididas em quatro grupos de seis animais, e foram submetidas à alimentação com rações contendo os seguintes níveis de torta de girassol: 0,$0 ; 5,0 ; 10,0$ e 20,0\%.

No segundo experimento avaliou-se os níveis de inclusão de torta de girassol em dietas de matrizes lactantes. O período experimental foi de 21 dias, iniciando no dia do parto. Os tratamentos avaliados foram 0,$0 ; 5,0 ; 10,0$ e $20,0 \%$ de inclusão de torta de girassol nas rações.

O delineamento experimental utilizado para ambas as avaliações foi o de blocos completamente casualizados, com quatro tratamentos e seis repetições, onde o bloco foi representado pela ordem do parto, sendo os animais de $1 .^{\circ}$ e $2 .^{\circ}$ partos pertencentes ao bloco 1 , os animais de $3 .^{\circ} \mathrm{e} 4 .^{\circ}$ partos ao bloco 2 e os de $5 .^{\circ}$ ou $6 .^{\circ}$ partos ao bloco 3 .

A torta, fornecida pela EMBRAPA - Centro Nacional de Pesquisa de Soja, Londrina, foi obtida por meio de prensagem mecânica contínua, sob temperatura média de $60^{\circ} \mathrm{C}$ e pressão de $200 \mathrm{~kg} / \mathrm{cm}^{2}$. A sua composição nutricional, com base na matéria natural, apresentou $92,4 \%$ de matéria seca, 22,2\% de proteína bruta, $22,1 \%$ de extrato etéreo, 23,3\% de fibra bruta, $4,7 \%$ de cinzas, $0,35 \%$ de cálcio e $0,70 \%$ de fósforo. Para a energia metabolizável foi considerado o valor de $3.247 \mathrm{Kcal} / \mathrm{kg}$, obtido por Silva et al. (2002).

Os níveis totais de lisina e metionina da torta de girassol foram estimados a partir dos valores presentes no farelo de girassol (NATIONAL RESEARCH COUNCIL - NRC, 1998) e corrigidos da extração de óleo. 
As rações foram formuladas visando atender as exigências nutricionais mínimas dos suínos nas fases de gestação e lactação (NRC, 1998), sendo isoenergéticas, isoprotéicas e isolisínicas.
Os ingredientes, a composição percentual e os valores calculados das rações experimentais de gestação e de lactação encontram-se apresentadas, respectivamente, nas Tabelas 1 e 2 .

Tabela 1. Composição percentual e calculada das rações experimentais para matrizes em gestação

\begin{tabular}{|c|c|c|c|c|}
\hline \multirow{2}{*}{ Ingredientes (\%) } & \multicolumn{4}{|c|}{ Tratamentos (níveis de inclusão de torta de girassol) \% } \\
\hline & 0,0 & 5,0 & 10,0 & 15,0 \\
\hline Milho & 64,691 & 65,793 & 62,712 & 56,551 \\
\hline Farelo de soja & 20,946 & 19,684 & 17,745 & 13,866 \\
\hline Farelo de trigo & 8,000 & 4,000 & 4,000 & 4,000 \\
\hline Torta de girassol & 0,000 & 5,000 & 10,000 & 20,000 \\
\hline Núcleo reprodução ${ }^{1}$ & 4,000 & 4,000 & 4,000 & 4,000 \\
\hline Óleo de soja & 2,028 & 1,153 & 1,133 & 1,091 \\
\hline Sal & 0,250 & 0,250 & 0,250 & 0,250 \\
\hline L-Lisina-HCl 78\% & 0,085 & 0,120 & 0,160 & 0,242 \\
\hline Total & 100,000 & 100,000 & 100,000 & 100,000 \\
\hline \multicolumn{5}{|l|}{ Valores calculados $^{2}$} \\
\hline Energia metabol. (kcal/kg) & 3150 & 3150 & 3150 & 3150 \\
\hline Proteína bruta $(\%)$ & 16,500 & 16,500 & 16,500 & 16,500 \\
\hline Extrato etéreo (\%) & 4,681 & 4,816 & 5,781 & 7,710 \\
\hline Fibra bruta $(\%)$ & 3,340 & 4,085 & 5,063 & 7,018 \\
\hline Cálcio (\%) & 1,125 & 1,133 & 1,142 & 1,162 \\
\hline Fósforo total (\%) & 0,728 & 0,715 & 0,735 & 0,769 \\
\hline Lisina total $(\%)$ & 0,880 & 0,880 & 0,880 & 0,880 \\
\hline Metionina Total (\%) & 0,263 & 0,274 & 0,281 & 0,297 \\
\hline
\end{tabular}

${ }^{1}$ Núcleo reprodução por kg de produto: vit. A, 200.000 UI; vit. D3, 40.000; vit. E, 500 mg; vit. B1, 25 mg; vit. B2, 97 mg; vit. B6, 25 mg; vit. B12, $400 \mathrm{mcg}$; vit. K3, $25 \mathrm{mg}$; ácido fólico, $31 \mathrm{mg}$; ácido pantotênico, $370 \mathrm{mg}$; biotina, 3,6 mg; cloreto de colina, $3000 \mathrm{mg}$; niacina, $500 \mathrm{mg}$; cálcio, 255 g; fósforo, $95 \mathrm{~g}$; sódio, 47,5 g; cobre, $370 \mathrm{mg}$; cobalto, 3,6 mg; ferro, $2250 \mathrm{mg}$; iodo, 5,3 mg; manganês, $780 \mathrm{mg}$; selênio, 6,5 mg; cromo, 5,5 mg; zinco, $2600 \mathrm{mg}$; flúor (máx.), $900 \mathrm{mg}$; antioxidante, $250 \mathrm{mg}$; solubilidade do fósforo em ácido cítrico a $2 \%$ (mín.), $95 \%$. ${ }^{2}$ Valores calculados com base nas tabelas de Rostagno et al. (2005).

Tabela 2. Composição percentual e calculada das rações experimentais para a avaliação das matrizes em lactação

\begin{tabular}{lcccc}
\hline \multirow{2}{*}{ Ingredientes (\%) } & \multicolumn{3}{c}{ Tratamentos (níveis de inclusão de torta de girassol) \% } \\
& 0,0 & 5,0 & 10,0 & 20,0 \\
\hline Milho & 66,093 & 63,012 & 59,932 & 53,771 \\
Farelo de soja & 27,926 & 25,987 & 24,047 & 20,168 \\
Torta de girassol & 0,000 & 5,000 & 10,000 & 20,000 \\
Núcleo reprodução ${ }^{1}$ & 4,000 & 4,000 & 4,000 & 4,000 \\
Óleo de soja & 1,625 & 1,604 & 1,583 & 1,542 \\
Sal & 0,250 & 0,250 & 0,250 & 0,250 \\
L-Lisina-HCl 78\% & 0,106 & 0,147 & 0,188 & 0,269 \\
\hline Total & 100,000 & 100,000 & 100,000 & 100,000 \\
Valores calculados ${ }^{2}$ & & & 3200 & \\
Energia metabol. (kcal/kg) & 3200 & 3200 & 18,500 & 18,500 \\
Proteína bruta (\%) & 18,500 & 18,500 & 6,046 & 7,975 \\
Extrato etéreo (\%) & 4,116 & 5,081 & 5,059 & 7,015 \\
Fibra bruta (\%) & 3,104 & 4,081 & 1,159 & 1,178 \\
Cálcio (\%) $\%$ ) & 1,140 & 1,150 & 0,729 & 0,760 \\
Fósforo total (\%) & 0,692 & 0,709 & 1,050 \\
Lisina total (\%) & 1,050 & 1,050 & 0,309 \\
Metionina Total (\%) & 0,293 & 0,301 & 0,324 \\
\hline
\end{tabular}

'Núcleo reprodução por kg de produto: vit. A, 200.000 UI; vit. D3, 40.000; vit. E, 500 mg; vit. B1, 25 mg; vit. B2, 97 mg; vit. B6, 25 mg; vit. B12, $400 \mathrm{mcg}$; vit. K3, $25 \mathrm{mg}$; ácido fólico, $31 \mathrm{mg}$; ácido pantotênico, $370 \mathrm{mg}$; biotina, $3,6 \mathrm{mg}$; cloreto de colina, $3000 \mathrm{mg}$; niacina, $500 \mathrm{mg}$; cálcio, 255 g; fósforo, $95 \mathrm{~g}$; sódio, 47,5 g; cobre, $370 \mathrm{mg}$; cobalto, 3,6 mg; ferro, $2250 \mathrm{mg}$; iodo, 5,3 mg; manganês, $780 \mathrm{mg}$; selênio, 6,5 mg; cromo, 5,5 mg; zinco, $2600 \mathrm{mg}$; flúor (máx.), $900 \mathrm{mg}$; antioxidante, $250 \mathrm{mg}$; solubilidade do fósforo em ácido cítrico a 2\% (mín.), $95 \%$.

${ }^{2}$ Valores calculados com base nas tabelas de Rostagno et al. (2005). 
Para as matrizes gestantes as rações foram fornecidas uma vez ao dia, pela manhã, na quantidade de $2,5 \mathrm{~kg}$, dos 80 aos 110 dias de gestação. As matrizes foram alojadas em gaiolas individuais com acesso irrestrito à água.

As matrizes lactantes, alojadas individualmente em celas parideiras, receberam ração quatro vezes ao dia, desde o dia do parto até o desmame, realizado aos 21 dias, e tiveram acesso ilimitado à água através de bebedouros do tipo chupeta com vazão superior a 2 litros por minuto. Em cada trato alimentar a quantidade de ração fornecida era baseada no atendimento da sensação de fome da matriz, sendo que as eventuais sobras de ração eram retiradas do cocho para o cálculo do consumo efetivo.

No experimento com matrizes gestantes foi avaliada a espessura de toucinho no ponto P2, medida na altura da última costela a seis centímetros da linha mediana, através de ultra-som de 3 camadas (Renco Lean Meater ${ }^{\circledR}$ Series 12), aos 80 e 110 dias de gestação e ao desmame, aos 21 dias de lactação. Como parâmetros de desempenho reprodutivo foram observados o número de leitões nascidos totais, nascidos vivos, natimortos, mumificados, peso ao nascer, peso das placentas, número de desmamados, peso ao desmame e dias de intervalo desmame-cio.

$\mathrm{Na}$ avaliação com matrizes lactantes a espessura de toucinho (P2) foi medida 1 dia antes do parto e no dia do desmame. Também foram avaliados o número de leitões nascidos totais, nascidos vivos, natimortos, mumificados, peso ao nascer, peso da placenta, número de leitões desmamados, peso ao desmame e o intervalo desmame-cio.
Durante a lactação, dentro dos grupos experimentais, as leitegadas foram uniformizadas de acordo com o peso ao nascer e o número de leitões.

$\mathrm{O}$ modelo matemático utilizado para a análise dos dados foi: $Y i j=m+T i+B j+E i j$ onde: $Y i j=e ́$ $\mathrm{o}$ valor observado relativo à parcela que recebeu $\mathrm{o}$ tratamento i no bloco $\mathrm{j} ; \mathrm{m}=$ média geral; $\mathrm{Ti}=$ efeito do tratamento $\mathrm{i} ; \mathrm{Bj}=$ efeito do bloco $\mathrm{j}$; Eij = erro experimental. Os dados obtidos foram submetidos à análise da variância, com derivação dos polinômios (análise de regressão), utilizando-se o programa SAEG (UNIVERSIDADE FEDERAL DE VIÇOSA - UFV, 1997).

\section{Resultados e Discussão}

Não foram verificadas (Tabelas 3 e 4), em ambos experimentos, diferenças $(\mathrm{P}>0,05)$ sobre a espessura de toucinho com a inclusão da torta de girassol nas rações. Estes resultados demonstram que o ingrediente possui a capacidade, mesmo sob a inclusão de $20 \%$ nas rações de fêmeas gestantes, de manter uma adequada reserva corporal no período pré-parto, com repercussões positivas na lactação subseqüente, garantindo um imediato cio pósdesmame e conseqüente novo ciclo gestacional. Nas matrizes lactantes os tratamentos também mantiveram os valores da espessura de toucinho, ao longo de todo o período avaliado, sob padrões idênticos aos observados nas porcas que consumiram rações a base de milho e farelo de soja, sugerindo adequada sustentação para as reservas de gordura da matriz.

Tabela 3. Médias e desvio padrão da espessura de toucinho de matrizes que receberam torta de girassol durante o período de gestação.

\begin{tabular}{llcl}
\hline $\begin{array}{l}\text { Níveis de torta de girassol } \\
\%\end{array}$ & \multicolumn{3}{c}{ Espessura de toucinho $(\mathrm{mm})$} \\
\hline 0,0 & $13,66 \pm 2,58$ & 110 dias gestação & 21 dias lactação \\
5,0 & $12,66 \pm 3,55$ & $14,83 \pm 3,19$ & $14,16 \pm 2,56$ \\
10,0 & $12,00 \pm 3,89$ & $14,83 \pm 4,17$ & $13,83 \pm 3,06$ \\
20,0 & $11,33 \pm 3,44$ & $14,33 \pm 3,82$ & $12,50 \pm 2,88$ \\
\hline Efeito da regressão & $\mathrm{NS}$ & $13,33 \pm 3,20$ & $12,66 \pm 3,26$ \\
\hline Coeficiente de variação $(\%)$ & 24,89 & $\mathrm{NS}$ & $\mathrm{NS}$ \\
\hline
\end{tabular}

NS - Não significativo $(\mathrm{P}>0,05)$ 
Tabela 4. Médias e desvio padrão da espessura de toucinho de matrizes que receberam torta de girassol durante o período de lactação.

\begin{tabular}{lll}
\hline Tratamentos & Espessura de toucinho $(\mathrm{mm})$ & \\
Níveis de torta de girassol & 1 dia pré-parto & 21 dias de lactação \\
\hline $0 \%$ & $12,50 \pm 2,16$ & $11,00 \pm 1,09$ \\
$5 \%$ & $11,83 \pm 1,60$ & $10,83 \pm 1,94$ \\
$10 \%$ & $16,00 \pm 5,01$ & $14,00 \pm 4,24$ \\
$20 \%$ & $14,83 \pm 5,19$ & $13,66 \pm 4,58$ \\
\hline Efeito da regressão & $\mathrm{NS}$ & $\mathrm{NS}$ \\
\hline Coeficiente de variação (\%) & 25,39 & 6,76 \\
\hline
\end{tabular}

NS - Não significativo $(\mathrm{P}>0,05)$

Os resultados para o número de leitões nascidos totais, nascidos vivos e para o peso da leitegada ao nascer, de acordo com os níveis de inclusão da torta de girassol nas rações de gestação e lactação estão, respectivamente, apresentados nas Tabelas 5 e 6.

Tabela 5. Médias e desvio padrão do número de leitões nascidos totais, nascidos vivos, peso da leitegada ao nascer, número de leitões desmamados e peso da leitegada ao desmame, consumo diário de ração e dias de intervalo desmamecio de matrizes que receberam torta de girassol 2durante o período de gestação.

\begin{tabular}{|c|c|c|c|c|c|c|}
\hline \multicolumn{7}{|c|}{ Níveis de torta de girassol \% } \\
\hline & 0,0 & 5,0 & 10,0 & 20,0 & ER & $\mathrm{CV} \%$ \\
\hline Nascidos Totais & $12,8 \pm 3,06$ & $12,7 \pm 3,20$ & $14,0 \pm 2,82$ & $13,2 \pm 2,31$ & NS & 22,0 \\
\hline Nascidos Vivos & $12,2 \pm 2,48$ & $11,8 \pm 3,43$ & $13,7 \pm 2,94$ & $12,8 \pm 2,48$ & NS & 22,1 \\
\hline $\begin{array}{l}\text { Peso da Leitegada ao } \\
\text { Nascer }(\mathrm{kg})\end{array}$ & $18,3 \pm 3,44$ & $17,3 \pm 3,14$ & $21,3 \pm 0,98$ & $18,5 \pm 3,08$ & NS & 13,1 \\
\hline Número de Desmamados & $9,7 \pm 1,63$ & $10,5 \pm 2,58$ & $11,7 \pm 1,86$ & $11,0 \pm 1,41$ & NS & 16,8 \\
\hline $\begin{array}{l}\text { Peso da Leitegada } \\
\text { Desmame }(\mathrm{kg})\end{array}$ & $57,8 \pm 8,84$ & $62,6 \pm 1,99$ & $69,3 \pm 10,30$ & $63,3 \pm 9,70$ & NS & 15,0 \\
\hline $\begin{array}{l}\text { Intervalo Desmame-cio } \\
\text { (dias) }\end{array}$ & $5,0 \pm 1,26$ & $5,2 \pm 1,72$ & $4,8 \pm 0,75$ & $5,2 \pm 0,75$ & NS & 24,25 \\
\hline
\end{tabular}

Tabela 6. Médias e desvio padrão do número de leitões nascidos totais, nascidos vivos e peso da leitegada ao nascer de matrizes que receberam torta de girassol durante o período de lactação.

\begin{tabular}{lcccccc}
\hline \multicolumn{7}{c}{ Níveis de torta de girassol \% } \\
\hline & 0,0 & 5,0 & 10,0 & 20,0 & ER & CV \% \\
\hline Nascidos Totais & $13,2 \pm 0,75$ & $13,2 \pm 1,47$ & $13,5 \pm 1,04$ & $13,7 \pm 1,63$ & NS & 9,9 \\
Nascidos Vivos & $12,7 \pm 0,81$ & $12,8 \pm 1,16$ & $13,3 \pm 1,03$ & $13,3 \pm 1,36$ & NS & 8,7 \\
Peso da Leitegada ao Nascer (kg) & $21,3 \pm 2,94$ & $19,9 \pm 1,02$ & $20,5 \pm 1,76$ & $20,7 \pm 2,80$ & NS & 10,8 \\
Número de Desmamados & $11,8 \pm 0,98$ & $11,7 \pm 0,81$ & $11,2 \pm 0,75$ & $11,5 \pm 1,51$ & NS & 9,17 \\
Peso da Leitegada ao Desmame & $72,2 \pm 7,96$ & $67,8 \pm 9,80$ & $66,1 \pm 4,95$ & $69,8 \pm 0,87$ & NS & 12,85 \\
(kg) & $7,6 \pm 0,32$ & $7,0 \pm 1,12$ & $6,5 \pm 1,22$ & $6,4 \pm 1,15$ & LINEAR & 15,30 \\
Consumo Diário de Ração (kg) & $4,6 \pm 0,81$ & $5,0 \pm 0,89$ & $5,7 \pm 1,36$ & $4,8 \pm 1,94$ & NS & 26,61 \\
Intervalo Desmame-cio (dias) & $4,6,0$
\end{tabular}

$\mathrm{ER}=$ Efeito da regressão $\quad \mathrm{CV}=$ Coeficiente de variação $\quad \mathrm{NS}-\mathrm{Não}$ significativo $(\mathrm{P}>0,05) \quad{ }^{1} \mathrm{Y}=7,92917-0,421333 \mathrm{X}\left(\mathrm{R}^{2}=0,19\right)$ 
Não foram observadas para todos os tratamentos experimentais nas fases de gestação e de lactação diferenças $(\mathrm{P}>0,05)$ sobre o número de leitões nascidos totais, nascidos vivos e sobre o peso da leitegada ao nascimento. Também não houve diferença para o número de natimortos e mumificados para matrizes gestantes submetidas aos tratamentos experimentais, que se apresentaram extremamente baixos (considerando todos os tratamentos observou-se 0,28 e 0,16 natimortos e mumificados, respectivamente). Estes resultados mostram que a torta de girassol pode ser incluída em rações de fêmeas reprodutoras, fazendo com que estas atinjam números ao parto semelhantes aos obtidos com uma alimentação clássica, baseada em milho e farelo de soja.

O peso das placentas das matrizes alimentadas com diferentes níveis de torta de girassol no período final da gestação $(5,50 ; 5,06 ; 5,41$ e $4 ; 76 \mathrm{~kg}$ para os tratamentos com $0,5,10$ e $20 \%$ de torta de girassol, respectivamente) também não foi afetado por nenhum dos tratamentos $(\mathrm{P}>0,05)$, mantendo-se dentro do normal para a espécie suína (HARTOG; VASSEUR, 1994). Estes resultados demonstram que a inclusão do ingrediente dos 80 aos 110 dias de gestação, período de maior desenvolvimento fetal (ABREU; DONZELE; OLIVEIRA, 2005), e relacionado com o peso placentário, manteve os índices de crescimento da progênie dentro de padrões considerados normais.

Com relação ao número de leitões desmamados e ao peso ao desmame, a inclusão de diferentes níveis de torta de girassol nas rações de matrizes em gestação e em lactação (Tabelas 5 e 6, respectivamente) não determinou diferenças $(\mathrm{P}>0,05)$ entre os tratamentos para os parâmetros.

Também a inclusão da torta de girassol nas rações de porcas gestantes e lactantes não influenciou o intervalo desmame-cio. Este fato confirma que a resposta à retomada de um novo ciclo reprodutivo, condição relacionada ao estado sanitário e nutricional damatriz(ZANGERONIMO;ALMEIDA;FIALHO, 2006), apresentou-se dentro da normalidade para a espécie, indicando a qualidade do ingrediente para as rações nestas fases.

Os valores obtidos para o intervalo desmamecio se identificam com as observações de Vinsky et al. (2006), apud Amaral Filha, Wentz e Bortolozzo (2006), que atribuem que em condições de alimentação ad libitum no período de lactação a retomada do estro após o desmame é de 5,3 dias em média.

Com relação ao consumo de ração na fase final da gestação todos os animais receberam 2,5 $\mathrm{kg}$ de ração e demonstraram plena ingestão. Este quadro sugere que houve boa aceitação às rações independente dos tratamentos, mesmo que sob uma condição alimentar restrita. Para o consumo de ração na fase de lactação os resultados estão apresentados na Tabela 6.

O aumento dos níveis de inclusão da torta de girassol provocou uma diminuição no consumo de ração $(\mathrm{P} \leq 0,05)$, atribuída, provavelmente, ao maior teor de fibra nas rações com maior quantidade de torta. Todavia, o consumo ainda apresentou-se satisfatório para a fase, uma vez que os resultados de desempenho dos leitões ao desmame e o retorno ao cio das matrizes foi semelhante entre os tratamentos.

\section{Conclusão}

A torta de girassol pode ser utilizada em até $20 \%$ na ração de matrizes suínas em gestação e lactação, apresentando aceitabilidade das rações, mantendo apropriada a espessura de toucinho, intervalo desmame-cio e todos os demais parâmetros reprodutivos. 


\section{Referências}

ABREU, M. L. T.; DONZELE, J. L.; OLIVEIRA, R. F. M. Exigências e manejos nutricionais de matrizes suínas gestantes e lactantes. In: SEMINÁRIO INTERNACIONAL DE AVES E SUÍNOS, 4., 2005. Florianópolis. Anais... Florianópolis: AVESUI, 2005. p. 33-59.

AMARAL FILHA, W. S.; WENTZ, I.; BORTOLOZZO, F. P. Melhoramento da produtividade das leitoas. IN: BORTOLOZZO, F. P.; WENTZ, I. A fêmea suína de reposição: Suinocultura em ação. Porto Alegre: Pallotti, 2006. p. 101-116.

COSTA, M. C. R.; SILVA, C. A.; PINHEIRO, J. W.; FONSECA, N. A. N.; SOUZA, N. A. N.; SOUZA, N. E.; VISENTAINEIR, J. V.; BELÉ, J. C.; BOROSKY, J. C.; MOURINHO, F. L.; AGOSTINI, P.S. Utilização da torta de girassol na alimentação de suínos nas fases de crescimento e terminação: efeitos no desempenho e nas características de carcaça. Revista Brasileira de Zootecnia, Viçosa, v. 34, n. 5, p. 1581-1588, 2005.

HARTOG, L. A.; VASSEUR, P. C. Nutrition Reproduction interaction in sows. IN: COLE, D.J.A.; WISEMAN, J.; VARLEY, M. A. Principles of pig science. Leicestershire: Nottingham, 1994. p. 215-224.
NATIONAL RESEARCH COUNCIL - NRC. Nutrient requirements of swine. 10. ed. Washington: National Academy Press, 1998.

ROSTAGNO, H. S.; ALBINO, L. F. T., DONZELE, J. L.; GOMES, P. C.; OLIVEIRA, R. F.; LOPES, D. C.; FERREIRA, A. S.; BARRETO, S. L. T. Tabelas brasileiras para aves e suínos. 2. ed. Viçosa: Ed. da UFV, 2005.

SILVA, C. A.; PINHEIRO, J. W.; FONSECA, N. A. F.; CABRERA, L.; SARUBBI, J.; COSTA, M. C. R.; PACHECO, G. D.; TELLES, H.; HIDESHIMA, C. S.; MOURINHO, F. L.; BOROSKY, J. C. Digestibilidade da torta de girassol para suínos na fase de crescimento. In: CONGRESSO LATINO AMERICANO DE SUINOCULTURA, 1., 2002, Foz do Iguaçu. Anais... Concórdia: Embrapa Suínos e Aves, 2002. p. 219-220. CD-ROM

UNIVERSIDADE FEDERAL DE VIÇOSA - UFV. SAEG: sistema de análises estatísticas e genéticas. Versão 7.1. Viçosa: Ed. da UFV, 1997. (Manual do usuário).

ZANGERONIMO,M.G.;ALMEIDA, M. J.M.;FIALHO, E. T. Efeito da nutrição na reprodução de matrizes suínas. Revista do Conselho Federal de Medicina Veterinária e Zootecnia, Brasília, v. 12, n. 38, p. 61-75, 2006. 
